\title{
How Does Leader Humor Expression Influence Follower Outcomes? Exploring the Dual Process Model
}

\begin{abstract}
Using both experimental and field data, we examined how and what style of leader humor expression leads to positive work outcomes. We develop and test a dual process model (the affective mechanism and the cognitive mechanism) delineating the psychological process by which leader humor expressions influence follower outcomes. We test our model across two studies. Study 1 demonstrates in an experiment that the perceived funniness of leader humor causes followers to report greater positive affect as well as positive evaluation of the leader. Extending these findings into organizational field context, Study 2 surveys a sample of 211 employees and 47 managers and finds that employees' positive affect at work and their positive evaluation of their manager mediated the relationship between perceived funniness of manager's humor and employee performance. However, the mediation path of positive evaluation is negatively moderated by manager's humor style such that when the manager has a selfdeprecating humor style, the positive effect of perceived humor funniness will decrease. We also contribute to the leadership, affect and humor literature by suggesting the need to view leader humor expression as a perception by the recipient rather than an intention of the sender, proposing two features of leader humor expression (perceived humor funniness and humor style) that have been neglected by past research.
\end{abstract}

\section{Keywords:}

Perceived humor funniness; self-deprecating humor style; affect and emotion; in-role performance; OCB 
I suppose leadership at one time meant muscles; but today it means getting along with people.

- Mohandas K. Ghandi

"Humor" has been defined as any stimuli shared by an agent (i.e., a leader) with the target(s) (i.e., the followers) that is intended to be amusing to the target(s) (Cooper, 2005). Effective leaders are likely to utilize direct tactics to regulate their followers' affect, and specifically the use of humor (Gostick \& Christopher, 2008). A handful of studies do observe that leaders utilize more conscious tactics, such as the use of humor, to regulate followers' affect. (Avolio, Howell, \& Sosik, 1999). Indeed, in the popular press many anecdotes about charismatic leaders - such as those about Scott McNealy of Sun Microsystems and Herb Kelleher of Southwest Airlines - emphasize the use of humor by leaders to connect with and influence their employees (Hof, Rebello, \& Burrows, 1996; Katz, 1996). Although these observations and initial findings are encouraging with regrd to the value of leader humor expression at workplace, understanding exactly how leader humor expression influences team members' performance remains largely unexplored (Cooper, 2005). Crawford (1994) goes so far as to conclude that the use of humor is the most promising but least understood communication strategy utilized by leaders. Despite some recent theoretical speculations in human relations literature (Cooper, 2008; Robert \& Wilbanks, 2012), there lack a discussion of the psychological process underlying leader humor expression supported by empirical examinations. Our paper addresses this gap in the literature by specifically elucidating and empirically testing how leader humor expression influences follower performance with a dual process model.

The small but growing literature on the use of humor by leaders centers primarily on one aspect of humor expression - the frequency of leader's humor expression - without exploring 
other attributes associated with leader's humor expression. This has led some researchers to speculate that it is the frequency of leader's humor that engenders positive organizational outcomes, including enhanced team cohesiveness (Duncan, 1982), improvement in team morale (Gruner, 1997), and the creation of positive organizational culture (Clouse \& Spurgeon, 1995). However, empirical work seems to suggest that frequently expressing humor may also negatively influence employees' performance contingent on the expressing manager's leadership style (e.g., Avolio et al., 1999). These findings suggest that while frequent humor expression may be an important aspect of effective leadership, not all types of humor always increase leadership effectiveness. Therefore, instead of focusing on how often leaders express humor, as in previous research, our paper advances research on humor and leadership by examining two neglected features of leader's humor expression - how funny a leader's humor is perceived to be by the followers (humor funniness) and the style of leader's humor expression (self-deprecating versus other humor style).

We focus on humor's perceived funniness because not all humor expression is perceived to be amusing (Duncan, 1982; Maples, Dupey, Torres-Rivera, Phan, \& Garrett, 2001; Stearns, 1972) and the experience of amusement and laughter is associated with important intrapersonal and social benefits (Keltner, 2009). Reflecting on the definition of humor given above, the dominant view of humor rests on the assumption that an observer's judgment of the intention of the expression is key (i.e., the leader is telling a joke), but not its effect (i.e., the joke is funny). As long the observer perceive that the expression is intended to be humorous, it is considered humor, regardless how funny any one observer finds it (Cooper, 2005). We argue, however, that whether the observer perceives the humor attempt as amusing is likely to have a decisive impact on the effects of leader's humor attempt. While humor expression often leads to amusement in 
observers (Berger, 1976; Chapman \& Foot, 1976), not all humor attempts are perceived to be equally and effectively amusing. Indeed, the appreciation of humor is described as a uniquely individual response (Duncan, 1982; Maples et al., 2001; Stearns, 1972). In other words, what is amusing to one person is not necessarily amusing to another. Therefore, we propose the perceived funniness of a leader's humor expression may distinguish effective humor from ineffective humor. We focus on humor style because individuals tend to have a reliable and consistent style in which they express humor (Martin, Puhlik-Doris, Larsen, Gray, \& Weir, 2003). In particular, certain individuals often use a self-deprecating humor style that amuses others by doing or saying funny things at one's own expense (Martin et al., 2003). Unlike other types of humor expression, the impact of self-deprecating humor is really mixed as leaders could be viewed both positively and negatively under such circumstances. To resolve this paradox and help contribute to our understanding of leader humor expression, we examine whether this humor style is effective for leaders.

By examining how leader humor expression influences follower outcomes, we extend leadership, humor and affect research by detailing the process of how leader humor expression operate in organizational context. We report here two studies conducted to systematically examine the effects of perceived leader humor funniness and leader humor style. Study 1 investigates the effects of perceived leader's humor funniness on observers' affective experience and their evaluation of the leader in an experiment, establishing the direction of our model's causal arrow. Study 2 surveys employees and managers in organizations to examine whether perceived funniness of manager's humor is associated with leader effectiveness in the form of employees' in-role performance (IRP) and their organizational citizenship behaviors (OCB) in a 
working organization. Study 2 also examines how the benefits of perceived funniness are influenced by whether the manager's humor style is self-deprecating or not.

\section{TOWARD A THEORY OF HOW LEADER HUMOR EXPRESSION INFLUENCES}

\section{FOLLOWER OUTCOMES}

\section{Affective and Cognitive Benefits of Leader Humor Expression}

Guided by the Emotion as Social Information (EASI) model (Van Kleef, 2009), we argue for a dual-process in which leader humor influences followers, just as with other expressions of emotion. Specifically, leader expression of humor exerts an interpersonal influence on followers through both affective and cognitive mechanisms. According to the Emotion as Social Information (EASI) model, one individual's emotion expression elicits a reciprocal emotional reaction in others, which then influences others' subsequent behavior. In the case of humor, by sharing jokes with an employee, a manager is attempting to enhance the employee's day-to-day enjoyment at work (affective reaction), which is likely to positively benefit other aspects of the employee's behavior at work. In addition to changing people's affective reaction, the EASI model also proposes a cognitive mediating mechanism. This mechanism suggests an individual's emotion expression also provides important information about the expresser, which shapes observers' evaluation of the expresser. By being humorous, an employee's perceptions of their manager are likely to be positively affected, which in turn is also likely to positively benefit employee's work behavior. Although the expression of humor is not the same as the expression of one's emotion, the EASI model provides a useful framework to understand how leader's humor may influence followers. Figure 1 shows these two processes working simultaneously.

Insert Figure 1 here 
The affective mechanism. Affect is a general term referring to both emotion and mood (Grandey, 2008; Rosenberg, 1998). Leaders - especially immediate supervisors - play a significant role in influencing how followers feel at work (Côté \& Hideg, 2011; Van Kleef et al., 2009). Focusing on leader's mood, Sy and colleagues (2005) demonstrated that individuals who worked with a leader in a good mood in an ad-hoc group created by the experimenters felt more positive as a result. Compared to mood, a leader's humor may be a more direct and potent way to influence followers' affective experience. According to the Relief theory of humor (Berlyne, 1972; Meyer, 2000), humor is an effective strategy at relieving one's own and other's tension and negative emotions (Carnevale \& Isen, 1986; Isen, Daubman, \& Nowicki, 1987). Indeed, the most prototypical emotional reaction to humor is laughter, which is associated with the pleasant feeling. That is perhaps why people pay money to attend comedy shows.

However, just like not all comedians can make people laugh, exposure to humor does not necessarily always increase people's positive affect. The affect-enhancing effect of humor is likely to occur only when individuals perceive a leader's humor to be amusing. In contrast, humor that is not perceived to be funny may not have the desired effects or even backfire, despite its intention. Thus, followers' positive affective experience should be positively associated with the perceived funniness of leader's humor.

Hypothesis 1: Greater perceived funniness of a leader's humor expression by followers will predict followers' positive affect.

The cognitive mechanism. In addition to its impact on followers' affect, leader's humor expression is also likely to influence what followers think about the leader (Van Kleef, 2009). 
Perceived funniness of leader's humor expression may influence followers' evaluation of leader's competence. Various cognitive abilities are required to produce humor that is funny (Greengross \& Miller, 2008; Howrigan \& MacDonald, 2008). Thus, the successful use of humor (e.g., producing humor that are perceived funny enough by followers) can be a reliable indicator of a leader's abilities. Wasielewski (1985) suggested that being able to excite and enthuse followers is an important vehicle of social influence for leaders. Therefore, followers may come to perceive leaders who are able to regularly make them laugh as possessing more cognitive, emotional or social intelligence. When a leader's humor expression falls flat in front of followers, followers are not likely to perceive the leader as intelligent. Therefore, we propose that followers form a more favorable evaluation of their leader when they perceive the leader's humor expression to be funny.

Hypothesis 2: Greater perceived funniness of a leader's humor expression by followers will predict enhanced follower evaluation of the leader.

\section{Positive Affect and Employee Performance}

In-role performance (IRP) refers to those behaviors specified in and/or required by the job description of the employee (Janssen \& Van Yperen, 2004). Employees who experience positive affect as a result of interacting with their manager should have improved performance since positive affect enhances individuals' work motivation and their ability to solve problems and make decisions (Lyubomirsky, King, \& Diener, 2005). Experimental work has shown that even mild increase in positive affect can significantly improve participants' motivation to perform experimental tasks (Erez \& Isen, 2002). In addition, a sizable body of research also shows that positive affective experience increases individuals' cognitive flexibility (Forgas \& George, 2001), which facilitates problem solving and decision making on the job (Staw, Sutton, 
\& Pelled, 1994). When employees are feeling positive at work (compared to when they are bored or feeling negative), they should become more engaged with their work, which should in turn contribute to their performance.

The influence of positive affect on followers goes beyond IRP, but also acts on Organizational Citizenship Behaviors (OCBs). OCBs are those behaviors that benefit the organization and/or the individuals within it, but are not (typically) explicitly recognized by the formal reward system (Organ, 1988).Fredrickson and colleagues (Fredrickson, 1998; Fredrickson, Cohn, Coffey, Pek, \& Finkel, 2008) theorized that positive affect can motivate people's affiliative and social tendencies, which in turn should lead to more helping behavior at work. Indeed, organizational research has found that employees who are in a positive mood are more likely to engage in pro-social behaviors (Baron, 1997) and altruistic acts than those in a negative mood (George, 1991). Since the perceived funniness of leader's humor should enhance followers' positive affect, the following hypotheses are proposed.

Hypothesis 3a: Greater perceived funniness of a leader's humor expression will predict followers' in-role performance (IRP).

Hypothesis 3b: Greater perceived funniness of a leader's humor expression will predict followers' organizational citizenship behaviors (OCBs).

In summary, we argue that the perceived funniness of a leader's humor expression is likely to enhance followers' positive affect, which will predict greater IRP and OCB. Therefore, followers' positive affect should mediate the effect of perceived humor funniness on followers' IRP and OCB:

Hypothesis 4a: Followers' positive affect will mediate the relationship between perceived funniness of a leader's humor expression and followers' in-role performance (IRP). 
Hypothesis 4b: Followers' positive affect will mediate the relationship between perceived funniness of a leader's humor expression and followers' organizational citizenship behaviors (OCBs).

\section{Positive Evaluation of the Leader and Employee Performance}

Hypothesis 2 suggests that the expression of funny humor should increase followers' positive evaluation of the leader. Following from that, we argue that a positive evaluation of a leader can drive employee performance at work. Since all organizational leaders serve as representatives of the organization, when followers have more positive evaluation of them, followers will have better expectations about the company itself and their own future in it (Isaac, Zerbe, \& Pitt, 2001). When they expect their future in the company to be better, they are more motivated to work harder (in-role behaviors) and make extra contributions to the company (extra-role behaviors). Thus, we propose that greater perceived funniness of a leader's humor expression will predict followers' in-role performance (IRP) and organizational citizenship behaviors (OCB), mediated by followers' evaluation of their leader.

Hypothesis 5a: Followers' positive evaluation of their leader mediates the relationship between perceived funniness of a leader's humor expression and followers' in-role performance (IRP).

Hypothesis 5b: Followers' positive evaluation of their leader mediates the relationship between perceived funniness of a leader's humor expression and followers' organizational citizenship behaviors (OCBs).

\section{Self-deprecating Humor Style}

Self-deprecating humor refers to a style that amuses others by doing or saying funny things at one's own expense (Martin et al., 2003). In contrast to various other humor styles that 
have been clearly linked to functional or dysfunctional interpersonal outcomes (Martin et al., 2003), the interpersonal effect of the self-deprecating humor has received mixed reviews in the literature. Despite the generally negative connotation of self-deprecating humor (Coser, 1960), some research suggests this style of humor may reduce social distance and therefore increase followers' liking of the leaders (Romero \& Cruthirds, 2006). The literature also suggests that followers may attribute positive qualities to a leader who is able to make fun of the self (Romero $\&$ Cruthirds, 2006). Because of the inconsistent findings, we focus specifically on looking at the moderating role of self-deprecating humor on the effects of perceived humor funniness.

We argue that a leader's self-deprecating humor style will negatively moderate the positive effects of perceived humor funniness. Despite a positive affective effect, selfdeprecating humor style is likely to reduce the positive effects of perceived humor funniness through its impact on the cognitive mechanism. After all, by definition self-deprecating humor risks exposing one's own real shortcomings to others. Indeed, self-deprecating humor that is also funny may be particularly damaging to a leader's reputation because followers are laughing at the leader's deficiencies, as opposed to laughing with the leader. This is likely to suppress followers' positive evaluation of the leader. Therefore, we proposed that:

Hypothesis 6: Leader's self-deprecating humor style will moderate the relationship between perceived funniness and followers' positive evaluation of a leader, such that the relationship will be weaker when the leader displays more self-deprecating humor.

One could also argue that followers may perceive leaders who express self-deprecating humor as modest and therefore evaluate them positively. To test for this potential counter-effect, we examined our model with a Chinese sample for which leader modesty is highly valued because of cultural influence (Yi \& Ye, 2003). It is likely to serve as a conservative test of our model. 


\section{STUDY 1: AN EXPERIMENT ON THE EFFECTS OF LEADER HUMOR FUNNINESS}

The focus of Study 1 is to demonstrate the causal effects of perceived leader humor funniness on observers' reactions. We examined whether individuals would be more likely to experience positive affect and evaluate a leader more favorably when the leader expresses humor that is perceived to be relatively more or less funny.

\section{Methods}

Participants and Design. The experiment featured two between-subjects conditions: funny humor and less-funny humor. Fifty six participants (31 men and 25 women) were recruited from Amazon Mechanical Turk (Mturk) and were randomly assigned to one of the conditions. There were no differences in participants' age $(t=-.25, \mathrm{p}=\mathrm{ns})$, gender $(\mathrm{t}=-1.04, \mathrm{p}=\mathrm{ns})$, educational background $(\mathrm{t}=-0.36, \mathrm{p}=\mathrm{ns})$ or political affiliation $(\mathrm{t}=0.382, \mathrm{p}=\mathrm{ns})$ between the two conditions.

Procedure and Manipulation. Participants were invited to a study on leadership effectiveness. Following previous experimental procedure used to examine the impact of leader's anger expression (Tiedens, 2001), participants watched a video clip of a speech by President Obama. Perceived humor funniness was manipulated by exposing participants to one of two video clips. We used video stimuli to manipulate perceived humor funniness since video can provide dynamic and realistic cues (Grandey, Fisk, Mattila, Jansen, \& Sideman, 2005).In the funny humor condition, President Obama joked about his lack of energy in the first presidential debate with Mitt Romney at the Alfred Smith dinner. In the less funny humor condition, President Obama joked about his problems of getting a dog for the family in the first press conference after his first election. We matched the videos on important criteria, including humor frequency (i.e., each had one humor expression), length of the video clip, and humor style (i.e., 
both were self-deprecating). After watching the video clips, participants rated how funny they found the joke to be, as well as their positive affect and evaluation of President Obama.

\section{Measures}

Perceived humor funniness. Participants reported how funny they found the humor in the video to be using a seven-item scale (sample items include: "When I was watching the video, I think President Obama's jokes were funny", "When I was watching the video, I think President Obama told jokes that fell flat (reverse)". All items were scored on seven-point Likert Scale (1= "Strongly Disagree" 7 = "Strongly Agree"). The reliability of the scale was satisfactory $($ Cronbach Alpha $=0.90)$.

Positive affect. Participants rated their affective experience after the video using the tenitem positive-affect PANAS scale developed by Watson and colleagues (Watson et al., 1988). Sample items include "I feel enthusiastic" and "I feel attentive." The items were scored on a five-point Likert Scale ( $1=$ "very little" $5=$ "a lot").The reliability for this scale was satisfactory $($ Cronbach Alpha $=0.97)$.

Leader evaluation. After watching the video, Participants also provided their evaluation of President Obama using the four-item scale developed by Kervyn and colleagues (Kervyn, Yzerbyt, Judd, \& Nunes, 2009) . Sample items include "President Obama struck me as capable"; "President Obama seemed skilled", and "President Obama looked competent". All the items were scored on seven-point Likert scales ( 1 = "strongly disagree" 7 = "strongly agree"). The Cronbach alpha for the combined scale was 0.90 .

\section{Study 1 Results}

As expected, results showed that participants judged the humor in the funny humor condition to be significantly funnier than the less-funny humor condition $\left(\mathrm{Mean}_{\mathrm{high}}=5.24 \mathrm{vs}\right.$. 
Mean $\left._{\text {low }}=4.20 ; t=2.85, p<0.05\right)$. Table 1 displays the means and standard deviations of all variables.

Insert Table 1 about here

Confirmatory factor analyses were conducted for the validation of our measures. The CFA showed that the three-factor model (perceived humor funniness, positive affect, and leader evaluation) yielded a good model fit $\left(\chi^{2}(186)=381.02, \chi^{2} / \mathrm{df}<3, \mathrm{CFI}=0.94, \mathrm{NNFI}=0.93\right)$, while, alternative models combining perceived humor funniness and leader evaluation $\left(\chi^{2}(188)=\right.$ 438.42, $\left.\mathrm{CFI}=0.92, \mathrm{NNFI}=0.91, \Delta \chi^{2}(2)=57.40, \mathrm{p}<0.05\right)$, perceived humor funniness and work $\operatorname{affect}\left(\chi^{2}(188)=830.70, \mathrm{CFI}=0.88, \mathrm{NNFI}=0.87, \Delta \chi^{2}(2)=449.68, \mathrm{p}<0.05\right)$, and leader evaluation and work affect $\left(\chi^{2}(188)=533.10, \mathrm{CFI}=0.90, \mathrm{NNFI}=0.89, \Delta \chi^{2}(2)=152.08, \mathrm{p}<0.05\right)$ all yielded worse model fit. Thus, the CFA results support the discriminant validity of our measures.

Hypothesis 1 predicted that greater perceived funniness of a leader's humor would predict followers' positive affect. Consistent with this prediction, although President Obama used humor in both conditions, participants in the funny humor condition reported experiencing significantly more positive affect than those in the less-funny humor condition $\left(\mathrm{Mean}_{\text {high }}=3.98, \mathrm{SD}=0.78\right.$; Mean $\left._{\text {low }}=3.18, \mathrm{SD}=1.21 ; t=2.97, p<0.01\right)$. Therefore, Hypothesis 1 was supported. Hypothesis 2 predicted that greater perceived funniness of a leader's humor would predict followers' positive evaluation of the leader. Although he received favorable evaluation from participants in both conditions, participants in the funny-humor condition evaluated President Obama significantly more favorably than participants in the less-funny humor condition $\left(\mathrm{Mean}_{\text {high }}=5.82, \mathrm{SD}=0.71\right.$; $\left.\mathrm{Mean}_{\text {low }}=5.07, \mathrm{SD}=1.39 ; t=2.55, p<0.05\right)$. Therefore, Hypothesis 2 was supported. 


\section{Study 1 Discussion}

As one of the first studies to examine the effects of perceived funniness of leader humor expression, Study 1 provides initial evidence demonstrating the benefits of expressing humor that is perceived funny in leadership. While both videos involve humor expression, participants reported feeling significantly more positive affect when the humor is perceived to be funnier. In addition, participants also had a more favorable evaluation of the target when the humor expression was perceived to be funnier. This result establishes the causal link between expressing effective humor that is perceived to be funny and its affective and cognitive effects. Study 1 has two key limitations, however. although we employed an experimental procedure used by previous research (Tiedens, 2001), participants in the sample did not have a direct relationship with President Obama, which is the general limitation of many experimental studies of leader-follower relations. Second, Study 1 does not fully test our model. It only establishes the first crucial link in our model. It is possible that the affective and evaluative responses to leader's humor expression found in Study 1 may not translate into actual behavior in the workplace. Study 2 addresses both of these limitations by examining the impact of funny humor expression in real organizations with real working relationships. Therefore, we examine how managers' humor funniness can influence two employee behaviors at work: the IRP and OCB. We also look at how self-deprecating humor style of managers moderates the effects of humor funniness.

\section{STUDY 2: A SURVEY ON THE EFFECTS OF FUNNY HUMOR IN THE WORKPLACE}

\section{Methods}

Sample and Procedure. Participants surveyed were employees from three entertainment and service companies in northwest China. The companies operate in multiple sectors, such as restaurants and coffee shops. Although specific cultural components of humor may differ across 
countries - such as what type of humor is perceived to be funny, as it does across individuals, scholars have generally argued that the effects of humor expression should be similar (Duncan, 1982). Research suggests that Chinese leaders are expected to develop the qualities of modesty due to the influence of Confucianism (e.g., Yi \& Ye, 2003; Wah, 2010). As a consequence, we shall expect self-deprecating humor to be perceived more positively in Chinese settings than in Western ones. Our selection of Chinese sample thus serves as a conservative test of our hypothesis that Self-deprecating humor negatively impacts follower's evaluation of their leaders. In total, 233 staff questionnaires and their 47 group manager questionnaires were distributed. 211 sets of manager-subordinate dyads remained after excluding the incomplete questionnaires, with an average of 4.5 staff per manager. The overall response rate was $90.6 \%$. Managers who responded had an average age of 26.51 years $(\mathrm{SD}=4.87)$, an average job tenure of 3.98 years $(\mathrm{SD}=2.79)$, and more than half of them $(61.7 \%)$ were male. Staff have an average age of 24.1 years $(\mathrm{SD}=4.05)$, average job tenure of 1.63 years $(\mathrm{SD}=1.84)$, and most of them $(76.3 \%)$ were female. The profiles of the samples were presented separately in Table 2.

Insert Table 2 about here

Both employees and managers completed informed consent forms and were assured individual confidentiality before participating in the study. All the questionnaires used in the study were back-translated. A native speaker first translated the materials from English to Chinese. After that, another native speaker translated the Chinese version back to English to confirm consistency and clarity. To prevent common method variance (Podsakoff, MacKenzie, Lee, \& Podsakoff, 2003), Study 2 collected the independent and dependent variables from two 
different sources. Employees rated their managers on perceived humor funniness and humor style. Employees also reported their positive affect at work and their evaluation of their managers. In a different questionnaire, managers rated the IRP and OCB of each employee.

\section{Measures}

Perceived Humor funniness. The same seven-item scale measuring individuals' perception in Study 1 was used in Study 2 with the change of referent from "Obama" to "my manager". Sample items include "My manager's jokes were funny"; "My manager told jokes that fell flat (reverse)". The item was scored on a seven-point Likert Scale $(1=$ "strongly disagree" $7=$ "strongly agree"). The Cronbach alpha for humor funniness scale was 0.96 .

Humor style. A three-item scale developed by Martin and colleagues (Martin et al., 2003) was used to measure manager's self-deprecating humor style. Sample Items include: "My manager often makes fun of/jokes about him/herself" ; "My manager often tries to make people like or accept him/her more by saying something funny about his/her own weakness". All items were scored on seven-point Likert Scale ( 1 = "almost never" 7 = "a lot"). The Cronbach alpha for self-deprecating humor style was 0.86 .

In-role performance (IRP). The five-item scale developed by Janssen and Yperen (2004) was used to measure employees' IRP. Sample items include “This employee always completes the duties specified in his/her job description": "This employee never neglects aspects of the job that he/she is obligated to performance". All the items were scored on seven-point Likert scales ( 1 = "strongly disagree" 7 = "strongly agree"). The Cronbach alpha for IRP was 0.85.

Organizational citizenship behavior (OCB).The 20-item scale developed by Farh and colleagues (Farh, Earley, \& Lin, 1997) was used to measure OCB. This OCB scale was lightly amended to fit the Chinese context. Sample items include "This employee is willing to stand up 
to protect the reputation of the company"; "This employee is willing to assist new colleagues to adjust to the work environment." All these items were scored on seven-point Likert scales of agreement ( 1 = "strongly disagree" 7 = "strongly agree"). The Cronbach alpha for the OCB measure was 0.91 .

Positive affect. The ten-item of the Job Affect Scale (JAS) developed by Brief, et al (Brief, Burke, George, Robinson, \& Webster, 1988) was used to measure employees' general positive affect. The staff members were asked to indicate how they usually feel at work; questions include “Active, strong, enthusiastic, excited, peppy, elated, relaxed, at rest, placid, calm”. All the items were scored on five-point Likert scales ( $1=$ "very little" $5=$ "a lot"). The Cronbach alpha for positive affect was 0.76 .

Evaluation of the manager. We adopted the three-item scale developed by Podsakoff and colleagues (Podsakoff, Todor, \& Schuler, 1983) to capture employees' positive evaluation of their manager. Sample items include "Nobody knows the jobs in my group better than my manager"; "Because of my manager's competence I usually go along with his/her advice on how I should do my job". All the items were scored on seven-point Likert scales of agreement $(1=$ "strongly disagree" $7=$ "strongly agree"). The Cronbach alpha for the measure was 0.90 .

\section{Control Variables}

Staff member gender, age and organizational tenure were used as controls in this study. Gender was coded 1 for male and 2 for female, while age and tenure were measured by number of years. We also controlled the similarities in gender and age between each manager and subordinate pair. These control variables were chosen following similar leadership studies (e.g., Liden, Wayne, \& Stilwell, 1993; Sparrowe, Soetijipto, \& Kraimer, 2006). The similarities of 
tenure and age were computed with Euclidean distances (Harrison \& Klein, 2007), i.e., the absolute values of differences in gender and age between manager and subordinate.

\section{Data Analysis Strategy}

Since our data are from 211 employees in 47 groups, the data has a nested structure. Therefore, in the data analysis, we need to first determine the appropriate level of analysis. Klein and Kozlowski (2000) suggested that nested data should be analyzed at the individual or group level, depending on whether the construct of interest is shared among the members of a group. Specifically, if individuals in a group have similar perception of a leadership characteristic, data should be analyzed at the group level; otherwise, data should be analyzed at the individual level. The degree to which humor is appreciated or perceived to be funny can be influenced by individual differences (Maples et al., 2001). Moreover, a manager may choose to express different humor to different employees. As such, employees in a work group may have different perceptions of how funny their manager's humor is. Therefore, it is more appropriate to analyze manager's humor funniness at the individual level. In contrast, humor style is a relatively stable characteristic of an individual (Martin et al., 2003). Therefore, employees should have consensus on what their manager's humor style is. So self-deprecating humor was analyzed at the group/manager level (Klein \& Kozlowski, 2000).

We also tested our theoretical assumption about treating humor style as a group-level construct by looking at a number of aggregation statistics that evaluate both within-group agreement and between-group variability of humor style (e.g., $r_{\mathrm{wg}}$, ICCs) (Hofmann, 1997). The average of $r_{w g}$ of humor style across 47 groups was 0.80 (median of $r_{w g}$ was 0.89 and nearly $80 \%$ of $r_{\mathrm{wg}}$ sere above 0.70 ), which meets the requirement for within-group agreement (James, Demaree, \& Wolf, 1984). In addition, ANOVA results showed that between-group variance in 
humor style was significantly different from zero, $\mathrm{F}(46,164)=1.46, p<0.05$. The ICC (1) derived from the ANOVA test was 0.29, and the ICC(2) was 0.65. Bliese (2000) and Liao and Chuang (2007) suggested that values of ICC(1) above 0.20 and ICC(2) above 0.70 indicate appropriate scores for group-level analysis. When the $\operatorname{ICC}(2)$ is smaller than 0.70 , if it is theoretically appropriate to aggregate the construct and the construct has big $\mathrm{r}_{\mathrm{wg}}$ and high between-group variance, it should be aggregated to the team level (Chen \& Bliese, 2002). Since humor style satisfies all criteria, we aggregated this measure to the group level.

Since the model consists of the cross-level constructs, Hierarchical Linear Modeling (HLM) is used in the analysis as it can simultaneously estimate the effects of factors from different levels on outcomes at the individual-level while maintaining the predictors' appropriate levels of analysis (Bryk \& Raudenbush, 1992; Hofmann, Morgeson, \& Gerras, 2003).

\section{Study 2 Results}

We conducted CFA (LISREL 8.7) to verify the discriminant validity of our measures. In the CFA, we use OCB's dimensional mean scores as its items to form the factor. We found that the six-factor model (perceived humor funniness, self-deprecating humor style, positive affect, positive evaluation, IRP, OCB) fit the data well $\left(\chi^{2}(480)=760.30, \chi^{2} / \mathrm{df}<2, \mathrm{RMSEA}=0.05\right.$, $\mathrm{CFI}=0.96, \mathrm{NNFI}=0.96, \mathrm{SRMR}=0.07$ ) and had a significantly better model fit than alternative models (e.g., five-factor model combining humor funniness and humor style, $\chi^{2}(485)=1152.17$, $\mathrm{RMSEA}=0.08, \mathrm{CFI}=0.93, \mathrm{NNFI}=0.92, \mathrm{SRMR}=0.09, \Delta \chi^{2}(5)=391.87, \mathrm{p}<0.05$; five-factor model combining humor funniness and evaluation of manager, $\chi^{2}(485)=1274.63$, RMSEA=0.09, $\mathrm{CFI}=0.91, \mathrm{NNFI}=0.90, \mathrm{SRMR}=0.10, \Delta \chi^{2}(5)=514.33, \mathrm{p}<0.05$; five-factor model combining perceived humor funniness and work affect, $\chi^{2}(485)=1404.69$, RMSEA=0.09, CFI=0.91, 
$\left.\mathrm{NNFI}=0.90, \mathrm{SRMR}=0.12, \Delta \chi^{2}(5)=644.39, \mathrm{p}<0.05\right)$. The CFA results supported the discriminant validity of the measures.

Table 3 presents the descriptive statistics and correlations among all the variables. Perceived humor funniness was significantly and positively related to positive affect, positive evaluation, OCB and IRP $(r=.18, .33, .34$, and .19 respectively, all $p<0.05)$. The two hypothesized mediators were significantly and positively related to OCB $(r=.38$ for positive evaluation; $r=.33$ for positive affect, both $p<0.05$ ), while, only positive affect was significantly related to IRP $(r=.48, p<0.05)$.

The null models using HLM (i.e., without entering any Level-1 and Level-2 predictors) for positive affect, positive evaluation, OCB and IRP were conducted. In null models, these dependent variables should have significant between-group variance to justify the usage of crosslevel analyses (e.g., HLM). The results of the null models for positive affect, positive evaluation, OCB and IRP were satisfactory: positive affect: $\tau_{00}=0.11, \mathrm{X}^{2}(46)=135.39, \mathrm{p}<0.05, \operatorname{ICC}(1)=0.30$; positive evaluation: $\tau_{00}=0.29, \chi^{2}(46)=72.31, \mathrm{p}<0.05, \operatorname{ICC}(1)=0.11$; OCB: $\tau_{00}=0.19, \chi^{2}(46)=$ 104.31, $<<0.05$, and $\operatorname{ICC}(1)=0.21$; IRP: $\tau_{00}=0.33, \chi^{2}(46)=146.01, p<0.05$, and $\operatorname{ICC}(1)=0.32$, justifying HLM as the appropriate analytic technique.

Insert Table 3 about here

Individual level relationships. Table 4 provides a summary of the models and results used to test the individual level relationships using HLM, controlling for follower gender, age, organizational tenure, and the gender and age similarities between manager and subordinate. 
Hypothesis 1 predicts that greater perceived funniness of leader's humor expression will predict followers' positive affect. Results revealed that perceived humor funniness was significantly related to employees' positive affect at work (Model $1, \beta=0.07, p<0.01$ ). That is, the funnier the manager's humor was to an employee, the more positive affect the employee reported at work. Therefore, consistent with Study 1, Hypothesis 1 is supported. When employees perceive their manager's humor expression to be funny, they are likely to report experiencing more positive affect. Hypothesis 2 predicts that greater perceived funniness of leader's humor expression will predict followers' positive evaluation of the leader. The result also provided support for this hypothesis (Model $2, \beta=0.30, p<0.01$ ). The funnier the manager's humor was to an employee, the more positive the employee evaluated the manager. Therefore, Hypothesis 2 is also supported. Hypothesis 3a predicts that greater perceived funniness of leader's humor expression predicts follower IRP. This hypothesis was also supported (Model 3, $\beta=0.10, p<0.05)$ - employee-rated manager's humor funniness is significantly related to manager-rated follower IRP. Hypothesis $3 \mathrm{~b}$ suggests that greater perceived funniness of leader's humor expression predicts follower OCB. Results also provided support for Hypothesis $3 \mathrm{~b}$ (Model 4, $\beta=0.18, p<0.01$ ). Employee-rated manager's humor funniness is significantly and positively related to manager-rated employees OCB.

Insert Table 4 about here

Hypothesis 4a predicts that followers' positive affect mediates the relationship between perceived funniness of a leader's humor expression and followers' IRP. Hypothesis $4 \mathrm{~b}$ predicts 
that followers' positive affect mediates the relationship between the leader's humor funniness perceived by followers and followers' OCB. Bootstrap analyses were conducted using methods described by Preacher and Hayes (2004). The bootstrap approach suggested by Preacher and Hayes (2004) is superior to the conventional mediation tests, like the mediation test procedure suggested by Baron and Kenny (1986) and Sobel test, since it does not require the assumptions about the shape of the distributions or the sampling distribution of the estimates (including the indirect-effect product $a^{*} b$ ). Preacher and Hayes (2004) also provided a SPSS Macro to compute the confidence interval of the indirect effect. With the SPSS Macro, the bootstrap results showed that the indirect effects of perceived humor funniness on IRP and OCB through positive affect were both significantly different from zero: the indirect effect of perceived humor funniness on IRP through positive affect had a point estimate of 0.06 , and a $95 \%$ confidence interval (CI) of between 0.02 and 0.12 ; while the indirect effect of perceived humor funniness on OCB had a point estimate of 0.03 , and $95 \% \mathrm{CI}$ of between 0.01 and 0.06 . Thus, Hypotheses $4 \mathrm{a}$ and $4 \mathrm{~b}$ are both supported - positive affect acts as a mediator in the relationships between perceived humor funniness and IRP, as well as between perceived humor funniness and OCB.

Hypotheses $5 \mathrm{a}$ and $5 \mathrm{~b}$ predicts that followers' positive evaluation of the leader mediate the relationship between perceived humor funniness and IRP and OCB. Bootstrap results showed that the indirect effects of perceived humor funniness on OCB through positive evaluation were significantly different from zero: the indirect effect of perceived humor funniness on OCB through positive evaluation had a point estimate of 0.05 , and $95 \%$ CI of between 0.02 and 0.09 . Thus, positive evaluation of leader mediates the relationship between perceived humor funniness and OCB. However, the indirect effect of perceived humor funniness on IRP through positive evaluation was not significantly different from zero: the indirect effect of perceived humor 
funniness on IRP through positive evaluation had a point estimate of 0.01 , and $95 \% \mathrm{CI}$ of between -.01 and 0.03 . Therefore, positive evaluation does not mediate the relationship between perceived humor funniness and IRP.

Cross-level relationship. Table 5 provides a summary of the models and results used to test the cross-level interaction relationship. Hypothesis 6 proposes a negative cross-level interaction between individual-level humor funniness and group-level humor style in predicting employees' positive evaluation of the manager. The "slopes-as-outcomes" model is used to test this hypothesis. In this model, the variance in the slope across groups is expected to be significantly related to humor style. The Model-3 results in Table 5 showed that the main effect of perceived humor funniness was significantly related to positive leader evaluation $(\gamma=-0.76, p<0.05)$, as well as the cross-level interaction $(\gamma=-0.16, p<0.05)$. These results provide support for Hypothesis 6 and suggest that group-level humor style (i.e., manager's self-deprecating humor style) decreases the individual-level influence of perceived humor funniness on employees' positive evaluation of the manager.

Insert Table 5 about here

To better understand the nature of this cross-level interaction, the interaction effect was plotted on a graph (see Figure 2). The procedure outlined by Aiken and West (1991) is applied that is, the relationship between perceived humor funniness and positive evaluation of the manager was plotted for high and low humor style (respectively defined as +1 and -1 standard deviation from the mean). additionally, a simple slopes analysis was conducted (Aiken \& West, 1991). For managers who employ low levels of self-deprecating humor, perceived humor 
funniness significantly predicts employees' positive evaluation of the manager (simple slope $=0.47, \mathrm{t}(43)=9.18, p<0.01)$. For managers who employ a high self-deprecating humor style, the relationship between perceived humor funniness and employees' evaluation is still significant, but with a significantly smaller magnitude (simple slope $=0.22, \mathrm{t}(43)=2.26, p<0.05$ ).

Insert Figure 2 about here

Supplementary moderated mediation test. As we hypothesized, positive evaluation of leaders would mediate the relationship between perceived humor funniness and IRP and OCB, with humor style as a moderator. We followed Edwards and Lambert's (2007) moderated path analysis approach to test this moderated mediation path. In our hypothesized model, the level-2 humor style moderates the relationship between perceived humor funniness and positive evaluation, which accords with the first-stage moderation model (Edwards \& Lambert, 2007; Pieterse, van Knippenberg, \& van Dierendonck, 2013; Preacher, Rucker, \& Hayes, 2007). The moderated path analytic procedure with MPlus showed that the link from perceived humor funniness to positive evaluation and then to OCB varied significantly as a function of manager's humor style (i.e., the first stage moderation). Specifically, the indirect relationship that the perceived humor funniness had with OCB via positive evaluation was significant (indirect effect $=0.09, p<0.05)$ when the manager scored low on self-deprecating humor style, but became non-significant when the manager scored high on self-deprecating humor style (indirect effect $=0.03, p>0.1)$. The difference in the effect size was significant $(\Delta \gamma=0.06, p<0.05)$. This result again supports $\mathrm{H} 5 \mathrm{~b}$ that positive evaluation mediates the relationship between perceived 
humor funniness and OCB. However, it is important to note that the indirect effects vary, depending on manager's self-deprecating humor style. For the indirect effect of perceived humor funniness on IRP, neither the indirect effects with high level of self-deprecating humor style (indirect effect=0.00, $p>0.1$ ), nor with low level of self-deprecating humor (indirect effect $=0.01$, $p>0.1)$ were significant. Thus, positive leader evaluation does not mediate the relationship between perceived humor funniness and IRP.

\section{Study 2 Discussion}

Study 2 directly addresses the weaknesses of Study 1. First, unlike participants in Study 1, followers have a meaningful leader-follower relationship with the leaders. Second, Study 2 extended findings in Study 1 by showing that followers' perception of managers' humor funniness is associated with employees' IRB and OCB. As with all studies, of course, Study 2 is not free of limitations. One could ask questions about the potential in this study for commonmethod bias. Although common-source bias was not a problem in the employee work outcomes, which were rated by managers rather than employees, it may still exist in the employee questionnaire part of the data because manager's self-deprecating humor style, evaluation of the manager and general affect at work were all assessed by employees' self-reported measures. To address this issue, Harman's one-factor test was used to check the existence of common method bias (Podsakoff et al., 2003). According to Harman's test, the first factor in an unconstrained exploratory factor analysis accounted for only $28 \%$ of the total variance. Thus, common method bias should not be a serious concern in the data. However, future research should measure predictors, mediators, and outcomes from different sources, at different time periods, and using different methods (e.g., survey, archival data, interview, observation) to completely eliminate the problem of common-method bias. 
While acknowledging limitations, one should not over-generalize from them. Our results add much that is novel and useful to the literature. For example, basic humor findings are replicated in a Chinese sample. This study also reveals the complexity of the humor expression equation and the underlying psychological processes, including both mediation and moderation. Future research should consider how the humor features and its interactions generate main and additional effects on additional attitudinal and behavioral outcomes, in a wider variety of settings, and at different levels of management.

\section{GENERAL DISCUSSION}

\section{Implications for theory}

The most important contribution our research make is to help illuminate the psychological processes underlying the effects of leader humor expression. We propose and test that leaders' humor expression influences followers through a dual process - by influencing followers' positive affect at work and their positive evaluation of the leader. Much existing humor research has elucidated the outcomes that humor can generate (Crawford, 1994; Csikszentmihalyi, 1996; Dienstbier, 1995; Isen et al., 1987; Murdock \& Ganim, 1993). However, there is little research empirically examining the psychological mechanisms through which these effects are generated. In the leadership context, our studies find that followers' general affect at work and evaluation of the leader play dominant roles linking perceived humor funniness of leaders and follower work outcomes. This process model helps integrate previous findings that examined the effects of humor on a number of outcomes.

Our findings also inform the leadership and humor literature by challenging the existing view of humor as an intention of the humor sender (in this case, a leader). In contrast, we argue for treating leader humor expression as a perception of the humor recipient (in this case, a 
follower). For leader humor expression to be effective, it has to be perceived as effectively amusing by followers.

Although a number of authors have shown the positive effects of leader's humor expression on followers (Avolio et al., 1999; Hughes \& Avey, 2009; Priest \& Swain, 2002; Vecchio et al., 2009), they have all simply focused their enquiries on how often humor is expressed by leaders without further distinguishing the features of humor that may elicit positive outcomes. Since humor can also lead to negative effects when used improperly (Avolio et al., 1999; Malone, 1980;Romero \& Cruthirds, 2006), it is important to identify when and how humor expression can lead to positive outcomes. Addressing this gap in the literature, our study shows that two features of humor expression (i.e., perceived humor funniness and humor style) each influence a number of different outcomes. The finding shows that in order to better understand the effectiveness of leader's humor expression, it is important to look at the features, rather than just the frequency of humor expression. Therefore, prior inconsistent findings on leadership style and humor effectiveness may be resolved by considering perceived humor funniness and humor style. Perhaps leadership style influences humor effectiveness differently because it influences how amusing a leader's humor is and the style of humor a leader uses.

Our results also contribute to the literature by showing the interactive effect of perceived humor funniness and humor style. Our study finds that self-deprecating humor hinders the positive effects of perceived humor funniness on followers' evaluation of the leader. When a leader's humor style is self-deprecating, the perceived funniness of the humor does not increase follower's positive evaluation of the leader as much as when the humor style is not selfdeprecating. When followers laugh at their leader, they do not evaluate their leader as being effective as when they laugh with their leader (i.e., and at other things/people). 
Lastly, while previous studies have looked principally at how humor influences followers' IRP (Avolio et al., 1999; Vecchio et al., 2009), the final contribution of this paper is that this study shows perceived leader humor funniness influences not only followers' IRP, but also OCBs. Our findings shows that humor not only influences followers' behaviors mandated by the organization (i.e., IRP), but those of a more spontaneous nature as well (i.e., OCB).

\section{Implications for managers}

This study offers significant implications for leaders using humor in the workplace. First, it highlights the tremendous positive impact that leader humor can have on the work outcomes of followers. However, this work highlights not only whether a leader displays humor or how much a leader attempts humor, as in previous researches, but how funny the humor is perceived to be by followers. Thus, a leader needs to pay special attention and take the perspective of the followers in striving to employ humor that followers will find amusing, in order to manage affect across the entire team. That is easier said than done, however, because there are significant individual differences in humor appreciation (i.e., what is funny to one person, such as the leader, may be not so funny to others - such as the followers), successful leaders need to be emotionally mature and intelligent to more effectively use humor to influence followers.

Our results also show that employing self-deprecating humor undermines the positive effects of perceived humor funniness on follower's positive evaluation of the leader. This finding provides some caution for humor expression. Although the ability to make followers laugh through humor expression can bring benefits, leaders need to be cautious when expressing selfdeprecating humor. The finding suggests that it is not as helpful for a leader to be laughed at by the followers compared with other styles of humor, even when the leader deliberately invites such a response and the leader's humor is quite funny. The results do not necessarily suggest that 
it is unhelpful for leaders to display self-deprecating humor, but rather that leaders should be careful when doing so. Under some situations, the detrimental effects of self-deprecating humor on the effects of perceived humor funniness will decrease or even disappear. Surely, if some strengths of a leader are already well-established, then maybe it is not detrimental for such a leader to be laughed at occasionally - in fact, such levity may serve to bridge or minimize any interpersonal gaps that exist because of highly different status between leader and follower. Moreover, the content of what a leader exposes in self-deprecating may matter a great deal. If the content is unimportant or not directly related to the work place, it may be less detrimental to be laughed at in any event. Future research should examine these and other such questions.

\section{CONCLUSION}

This paper began by asking questions about the psychological process underlying how leader attempts at humor translate into follower performance. A much better understanding of those issues has been achieved now in finding that perceived leader humor funniness and humor style influences the effectiveness of humor expression. We proposed and tested a dual process model in which leader humor expression influences various important outcomes - via influencing followers' positive affect generally and via influencing followers' evaluation of the leader specifically. In addition, we also contribute to the literature by showing the role played by self-deprecating humor with a conservative test on Chinese samples. Our study demonstrates the usefulness of looking into the psychological processes underlying leader-member relations and the use of humor. We hope that our paper will also encourage other scholars to pursue this fruitful avenue of enquiry. 


\section{REFERENCES}

Aiken, L., \& West, S. 1991. Multiple regression: Testing and interpreting interactions.

Newbury Park, CA: Sage.

Ashkanasy, N., \& Tse, B. 2000. Transformational leadership as management of emotion. In N. M. Ashkanasy;, C. E. J. Härtel;, \& W. Zerbe (Eds.), Emotions in the Workplace:

Research, Theory, and Practice: 221-235. Westport, CT: Quorum Books.

Avolio, B., Howell, J., \& Sosik, J. 1999. A funny thing happened on the way to the bottom line: Humor as a moderator of leadership style effects. The Academy of Management Journal, 42(2): 219-227.

Baron, R. 1997. The sweet smell of... helping: Effects of pleasant ambient fragrance on prosocial behavior in shopping malls. Personality and Social Psychology Bulletin, 23(5): 498-503.

Bass, B., \& Avolio, B. 1995. Multifactor leadership questionnaire: Technical report. Redwood City, CA: Mind Garden Inc.

Berger, A. 1976. Anatomy of the joke. Journal of Communication, 26(3): 113-115.

Berlyne, D. 1972. Humor and its kin. The psychology of humor: 43-60.

Bliese, P. 2000. Within-group agreement, non-independence, and reliability: Implications for data aggregation and analysis. In K. Klein, \& S. Kozlowski (Eds.), Multi-level theory, research, and methods in organizations: 349-381. San Francisco, CA: Jossey-Bass.

Brief, A., Burke, M., George, J., Robinson, B., \& Webster, J. 1988. Should negative affectivity remain an unmeasured variable in the study of job stress? Journal of Applied Psychology, 73(2): 193-198.

Bryk, A., \& Raudenbush, S. 1992. Hierarchical linear models. Newbury Park, CA: Sage.

Carnevale, P., \& Isen, A. 1986. The influence of positive affect and visual access on the discovery of integrative solutions in bilateral negotiation. Organizational Behavior and Human Decision Processes, 37(1): 1-13.

Chapman, A., \& Foot, H. 1976. Humour and laughter: Theory, research, and applications. Lodnon: Wiley.

Chen, G., \& Bliese, P. D. 2002. The role of different levels of leadership in predicting self-and collective efficacy: evidence for discontinuity. Journal of Applied Psychology, 87(3): 549-556.

Clouse, R., \& Spurgeon, K. 1995. Corporate analysis of humor. Psychology-A Quterley Journal of Human Behavior, 32(3/4): 1-24.

Cooper, C. 2005. Just joking around? Employee humor expression as an ingratiatory behavior. Academy of Management Review, 30(4): 765-776.

Cooper, C. (2008). Elucidating the bonds of workplace humor: A relational process model. Human Relations, 61(8), 1087-1115.

Coser, R. 1960. Laughter among colleagues. A study of the social functions of humor among the staff of a mental hospital. Psychiatry, 23(1): 81-96.

Côté, S., \& Hideg, I. 2011. The ability to influence others via emotion displays A new dimension of emotional intelligence. Organizational Psychology Review, 1(1): 53-71.

Crawford, C. 1994. Theory and implications regarding the utilization of strategic humor by leaders. Journal of Leadership \& Organizational Studies, 1(4): 53-68.

Csikszentmihalyi, M. 1996. Creativity: Flow and the Psychology of Discovery and Invention. New York: Harper Perennial. 
Dienstbier, R. 1995. The impact of humor on energy, tension, task choices, and attributions: Exploring hypotheses from toughness theory. Motivation and Emotion, 19(4): 255-268.

Duncan, W. 1982. Humor in management: Prospects for administrative practice and research. Academy of Management Review, 7(1): 136-142.

Edwards, J. R., \& Lambert, L. S. 2007. Methods for integrating moderation and mediation: a general analytical framework using moderated path analysis. Psychological methods, 12(1): 1-22.

Erez, A., \& Isen, A. 2002. The influence of positive affect on the components of expectancy motivation. Journal of Applied Psychology, 87(6): 1055-1066.

Farh, J., Earley, P., \& Lin, S. 1997. Impetus for Action: A Cultural Analysis of Justice and Organizational Citizenship Behavior in Chinese Society. Administrative Science Quarterly, 42(3): 421-444.

Forgas, J. P., \& George, J. M. 2001. Affective influences on judgments and behavior in organizations: An information processing perspective. Organizational Behavior and Human Decision Processes, 86(1): 3-34.

Fredrickson, B. 1998. What good are positive emotions? Review of General Psychology, 2(3): 300-319.

Fredrickson, B., Cohn, M., Coffey, K., Pek, J., \& Finkel, S. 2008. Open hearts build lives: Positive emotions, induced through loving-kindness meditation, build consequential personal resources. Journal of personality and social psychology, 95(5): 1045-1062.

George, J. 1991. State or trait: Effects of positive mood on prosocial behaviors at work. Journal of Applied Psychology, 76(2): 299-307.

Gostick, A., \& Christopher, S. 2008. The Levity Effect: Why it Pays to Lighten Up. Hoboben: John Wiley \& Sons.

Grandey, A. 2008. Emotions at work: A review and research agenda. In C. Cooper, \& J. Barling (Eds.), The SAGE Handbook of Organizational Behavior: Micro approaches, Vol. 1: 235-261. Thousand Oaks, CA: Sage.

Grandey, A., Fisk, G., Mattila, A., Jansen, K., \& Sideman, L. 2005. Is "service with a smile" enough? Authenticity of positive displays during service encounters. Organizational Behavior and Human Decision Processes, 96(1): 38-55.

Greengross, G., \& Miller, G. 2008. Dissing oneself versus dissing rivals: Effects of status, personality, and sex on the short-term and long-term attractiveness of self-deprecating and other-deprecating humor. Evolutionary Psychology, 6(3): 393-408.

Gruner, C. 1997. The game of humor: A comprehensive theory of why we laugh. New Brunswick, NJ: Transaction.

Harrison, D. A., \& Klein, K. J. 2007. What's the difference? Diversity constructs as separation, variety, or disparity in organizations. Academy of Management Review, 32, 1199-1228.

Hof, R., Rebello, K., \& Burrows, P. 1996. Scott McNealy's rising sun, Business Week, Vol. January 22: 66-73.

Hofmann, D. 1997. An overview of the logic and rationale of hierarchical linear models. Journal of Management, 23(6): 723-744.

Hofmann, D., Morgeson, F., \& Gerras, S. 2003. Climate as a moderator of the relationship between leader-member exchange and content specific citizenship: Safety climate as an exemplar. Journal of Applied Psychology, 88(1): 170-178.

Howrigan, D., \& MacDonald, K. 2008. Humor as a mental fitness indicator. Evolutionary Psychology, 6(4): 652-666. 
Hughes, L., \& Avey, J. 2009. Transforming with levity: humor, leadership, and follower attitudes. Leadership \& Organization Development Journal, 30(6): 540-562.

Isaac, R., Zerbe, W., \& Pitt, D. 2001. Leadership and motivation: The effective application of expectancy theory. Journal of Managerial Issues, 13(2): 212-226.

Isen, A., Daubman, K., \& Nowicki, G. 1987. Positive affect facilitates creative problem solving. Journal of Personality and Social Psychology, 52(6): 1122-1131.

James, L., Demaree, R., \& Wolf, G. 1984. Estimating within-group interrater reliability with and without response bias. Journal of Applied Psychology, 69(1): 85-98.

Janssen, O., \& Van Yperen, N. 2004. Employees' goal orientations, the quality of leader-member exchange, and the outcomes of job performance and job satisfaction. The Academy of Management Journal, 47(3): 368-384.

Katz, J. 1996. Is this the perfect place to work, Los Angeles Times Magazine, Vol. June 9: 32.

Keltner, D. 2009. Born to be good: The science of a meaningful life. New York, NY: WW Norton \& Company.

Kervyn, N., Yzerbyt, V. Y., Judd, C. M., \& Nunes, A. 2009. A question of compensation: the social life of the fundamental dimensions of social perception. Journal of Personality and Social Psychology, 96(4): 828-842.

Klein, K., \& Kozlowski, S. 2000. From micro to meso: Critical steps in conceptualizing and conducting multilevel research. Organizational Research Methods, 3(3): 211-236.

Liao, H., \& Chuang, A. 2007. Transforming service employees and climate: A multilevel, multisource examination of transformational leadership in building long-term service relationships. Journal of Applied Psychology, 92(4): 1006-1019.

Lyubomirsky, S., King, L., \& Diener, E. 2005. The benefits of frequent positive affect: does happiness lead to success? Psychological bulletin, 131(6): 803-855.

Malone, P. 1980. Humor: a double-edged tool for today's managers? The Academy of Management Review, 5(3): 357-360.

Maples, M. F., Dupey, P., Torres-Rivera, E., Phan, L. T., \& Garrett, M. T. 2001. Ethnic Diversity and the Use of Humor in Counseling: Appropriate or Inappropriate? Journal of Counseling \& Development, 79(1): 53-60.

Martin, R., Puhlik-Doris, P., Larsen, G., Gray, J., \& Weir, K. 2003. Individual differences in uses of humor and their relation to psychological well-being: Development of the Humor Styles Questionnaire. Journal of Research in Personality, 37(1): 48-75.

Meyer, J. C. 2000. Humor as a double - edged sword: Four functions of humor in communication. Communication theory, 10(3): 310-331.

Murdock, M., \& Ganim, R. 1993. Creativity and Humor: Integration and Incongruity. Journal of Creative Behavior, 27(1): 57-70.

Organ, D. 1988. Organizational citizenship behavior: The good soldier syndrome. Lexington, MA: Lexington books.

Pieterse, A. N., van Knippenberg, D., \& van Dierendonck, D. 2013. Cultural diversity and team performance: The role of team member goal orientation. Academy of Management Journal, 56(3): 782-804.

Podsakoff, P., MacKenzie, S., Lee, J., \& Podsakoff, N. 2003. Common method biases in behavioral research: A critical review of the literature and recommended remedies.

Journal of Applied Psychology, 88(5): 879-903.

Podsakoff, P., Todor, W., \& Schuler, R. 1983. Leader expertise as a moderator of the effects of instrumental and supportive leader behaviors. Journal of Management, 9(2): 173-185. 
Preacher, K., \& Hayes, A. 2004. SPSS and SAS procedures for estimating indirect effects in simple mediation models. Behavior Research Methods, 36(4): 717-731.

Preacher, K., Rucker, D., \& Hayes, A. 2007. Addressing moderated mediation hypotheses: Theory, methods, and prescriptions. Multivariate Behavioral Research, 42(1): 185-227.

Priest, R., \& Swain, J. 2002. Humor and its implications for leadership effectiveness. HumorInternational Journal of Humor Research, 15(2): 169-189.

Robert, C., \& Wilbanks, J. E. (2012). The wheel model of humor: Humor events and affect in organizations. Human Relations, 65(9), 1071-1099.

Romero, E., \& Cruthirds, K. 2006. The use of humor in the workplace. The Academy of Management Perspectives, 20(2): 58-69.

Rosenberg, E. 1998. Levels of analysis and the organization of affect. Review of General Psychology, 2(3): 247-270.

Seow Wah, S. 2010. Confucianism and Chinese leadership. Chinese management studies, 4(3), 280-285.

Staw, B. M., Sutton, R. I., \& Pelled, L. H. 1994. Employee positive emotion and favorable outcomes at the workplace. Organization Science, 5(1): 51-71.

Stearns, F. 1972. Laughing: Physiology, pathophysiology, psychology, pathopsychology, and development. Springfield: Charles Thomas.

Sy, T., Côté, S., \& Saavedra, R. 2005. The Contagious Leader: Impact of the Leader's Mood on the Mood of Group Members, Group Affective Tone, and Group Processes. Journal of Applied Psychology, 90(2): 295-305.

Tiedens, L. 2001. Anger and advancement versus sadness and subjugation: The effect of negative emotion expressions on social status conferral. Journal of Personality and Social Psychology, 80(1): 86-94.

Van Kleef, G. 2009. How emotions regulate social life: The emotions as social information (EASI) model. Current Directions in Psychological Science, 18(3): 184-188.

Van Kleef, G., Homan, A., Beersma, B., Van Knippenberg, D., Van Knippenberg, B., \& Damen, F. 2009. Searing sentiment or cold calculation? The effects of leader emotional displays on team performance depend on follower epistemic motivation. The Academy of Management Journal 52(3): 562-580.

Vecchio, R., Justin, J., \& Pearce, C. 2009. The Influence of Leader Humor on Relationships between Leader Behavior and Follower Outcomes. Journal of Managerial Issues, 21(2): 171-194.

Wasielewski, P. 1985. The emotional basis of charisma. Symbolic Interaction, 8(2): 207-222.

Yi, J. J., \& Ye, S. X. 2003. The Haier way: The making of a Chinese business leader and a global brand. Homa \& Sekey Books. 
TABLE 1

Study 1 Descriptive Statistics ${ }^{\mathrm{a}}$

\begin{tabular}{|c|c|c|c|c|c|c|}
\hline & Variable & Mean & $\mathrm{SD}$ & 1 & 2 & 3 \\
\hline 1 & $\begin{array}{l}\text { Perceived humor } \\
\text { funniness }\end{array}$ & 5.36 & 1.03 & $(0.90)$ & & \\
\hline 2 & Positive evaluation & 5.46 & 1.14 & $0.68 * *$ & $(0.93)$ & \\
\hline 3 & Positive affect & 3.59 & 1.08 & $0.53 * *$ & $0.50 * *$ & $(0.90)$ \\
\hline
\end{tabular}

${ }^{\mathrm{a}} \mathrm{n}=56 . * p<0.05, * * p<0.01$.Cronbach alphas appear in parentheses along diagonal. 
TABLE 2 Profiles of Samples from Three Companies ${ }^{a}$

\begin{tabular}{|c|c|c|c|c|c|}
\hline Characteristics & Firm 1 & Firm 2 & Firm 3 & F test & Sig. \\
\hline Firm size (number of employees) & 120 & 72 & 41 & & \\
\hline Firm age (years) & 11 & 4 & 3 & & \\
\hline Respondent employee number & 107 & 67 & 37 & & \\
\hline Respondent employee age (years) & $25.21(4.18)$ & $22.30(3.58)$ & $24.19(3.29)$ & 11.82 & .00 \\
\hline Respondent employee tenure (years) & $2.32(2.23)$ & $1.07(0.99)$ & $0.65(0.66)$ & 18.33 & .00 \\
\hline Respondent supervisor age (years) & $27.92(5.87)$ & $24.47(3.09)$ & $26.13(2.70)$ & 2.5 & .09 \\
\hline Respondent supervisor tenure (years) & $5.02(2.78)$ & $3.20(2.53)$ & $2.32(2.17)$ & 4.19 & .02 \\
\hline \multicolumn{6}{|l|}{ Respondent employee gender (number) } \\
\hline Male & 25 & 19 & 6 & .97 & .38 \\
\hline Female & 82 & 48 & 31 & & \\
\hline \multicolumn{6}{|l|}{ Respondent supervisor gender (number) } \\
\hline Male & 14 & 10 & 5 & .13 & .88 \\
\hline Female & 10 & 5 & 3 & & \\
\hline
\end{tabular}

${ }^{\mathrm{a}}$ Numbers in parentheses are standard deviations. 
TABLE 3

Means, Standard Deviations and Correlations of the Variables

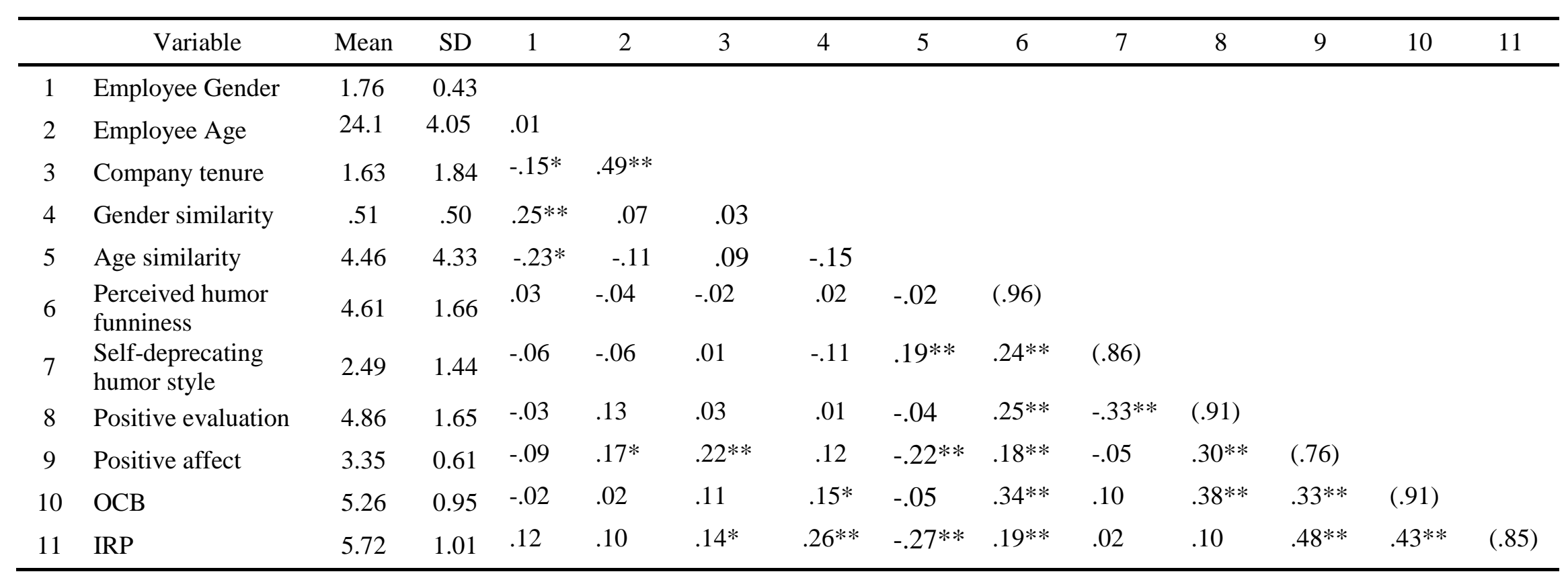

${ }^{\mathrm{a}} \mathrm{n}=211 . * p<0.05, * * p<0.01$.Gender was coded 1 for male and 2 for female.Cronbach alphas appear in parentheses along diagonal. 
TABLE 4

Effects of Perceived Humor Funniness on Follower Behaviors ${ }^{\text {a }}$

\begin{tabular}{ccccc}
\hline Variable & $\begin{array}{c}\text { Model 1 } \\
\text { Affect }\end{array}$ & $\begin{array}{c}\text { Model 2 } \\
\text { Evaluation }\end{array}$ & $\begin{array}{c}\text { Model 3 } \\
\text { IRP }\end{array}$ & $\begin{array}{c}\text { Model 4 } \\
\text { OCB }\end{array}$ \\
\hline Employee gender & -0.16 & -0.27 & 0.07 & -0.16 \\
Employee age & 0.01 & 0.03 & 0.01 & 0.00 \\
Company tenure & 0.05 & -0.02 & 0.07 & 0.05 \\
Gender similarity & 0.11 & .06 & $0.41^{*}$ & $0.34^{*}$ \\
Age similarity & $-0.03^{*}$ & -.02 & $-0.05^{*}$ & 0.00 \\
& & & & \\
Perceived humor funniness & $0.07^{* *}$ & $0.30^{* *}$ & $.10^{*}$ & $.18^{* * *}$ \\
$\mathrm{R}_{\text {within-group }}^{2}$ & $1.1 \%$ & $13.0 \%$ & $6.3 \%$ & $11.0 \%$ \\
Deviance & 339.74 & 730.62 & 546.34 & 530.92 \\
\hline
\end{tabular}

${ }_{\mathrm{n}}^{\mathrm{a}}=211 * p \leq 0.05, * * p \leq 0.01$.IRP for in-role performance. 
TABLE 5

Hierarchical Linear Modeling Results: Moderating Effects of Humor Style on Perceived Humor Funniness

\begin{tabular}{cccc}
\hline Variable & $\begin{array}{c}\text { Model 1 } \\
\text { Evaluation }\end{array}$ & $\begin{array}{c}\text { Model 2 } \\
\text { Evaluation }\end{array}$ & $\begin{array}{c}\text { Model 3 } \\
\text { Evaluation }\end{array}$ \\
Employee gender & -0.27 & -0.32 & -0.36 \\
Employee age & 0.03 & 0.04 & 0.03 \\
Company tenure & -0.02 & -0.01 & -0.02 \\
Gender similarity & 0.06 & 0.01 & 0.08 \\
Age similarity & -0.02 & -0.02 & -0.01 \\
Perceived humor funniness & $0.30 * *$ & $0.36^{* * *}$ & $.76^{* *}$ \\
Humor style & & 0.24 & -0.30 \\
Perceived humor & & & $-0.16 *$ \\
funniness*style & & & \\
$\mathrm{R}_{\text {within-group }}^{2}$ & $13.0 \%$ & $13.1 \%$ & $14.9 \%$ \\
Deviance & 730.62 & 722.81 & 717.95 \\
\hline
\end{tabular}

$\mathrm{a} * p<0.05, * * p<0.01$ 
FIGURE 1

Theoretical model

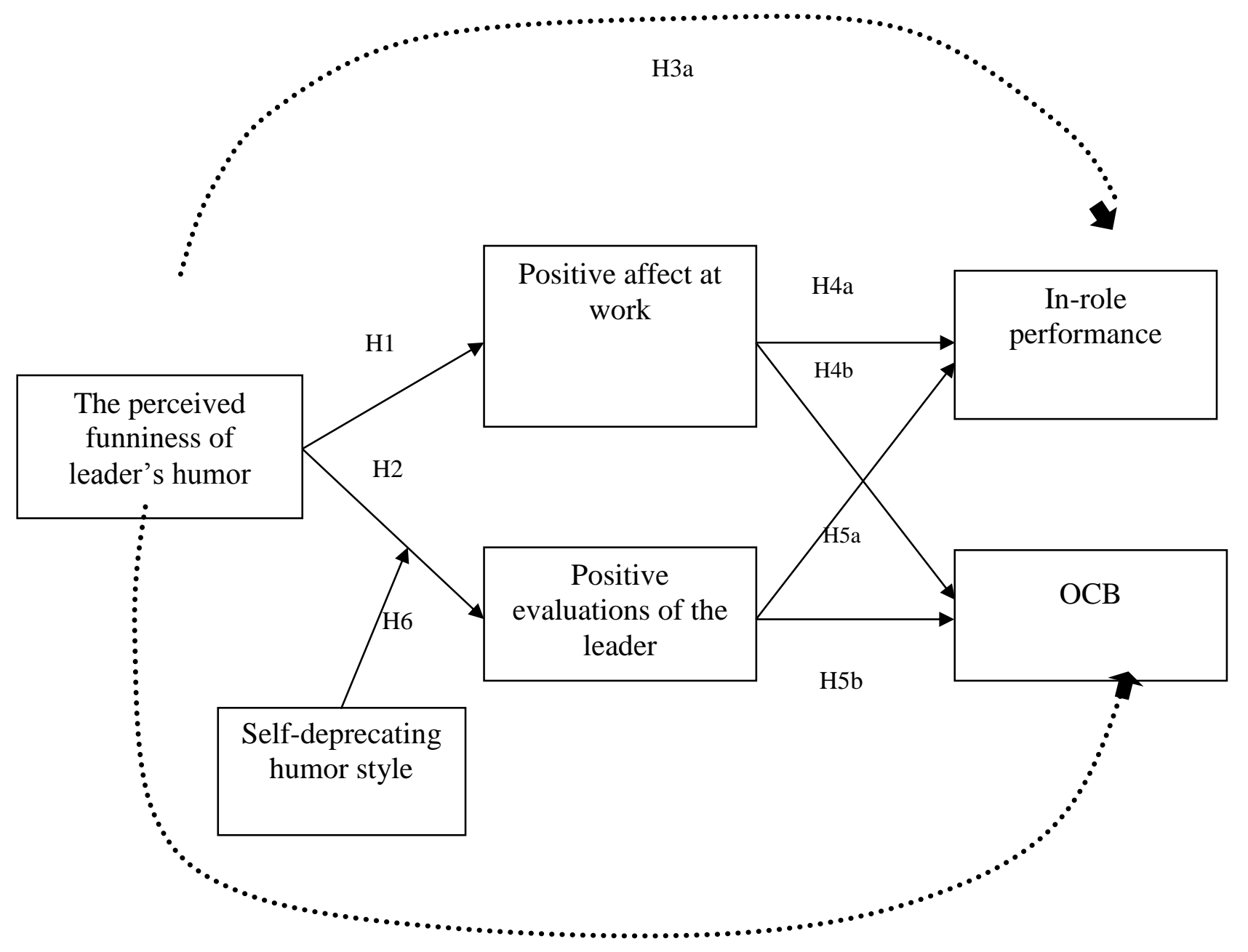

$\mathrm{H} 3 \mathrm{~b}$ 


\section{FIGURE 2}

\section{Positive Leader Evaluation as a Function of Perceived Humor Funniness and}

\section{Leader Humor Style}

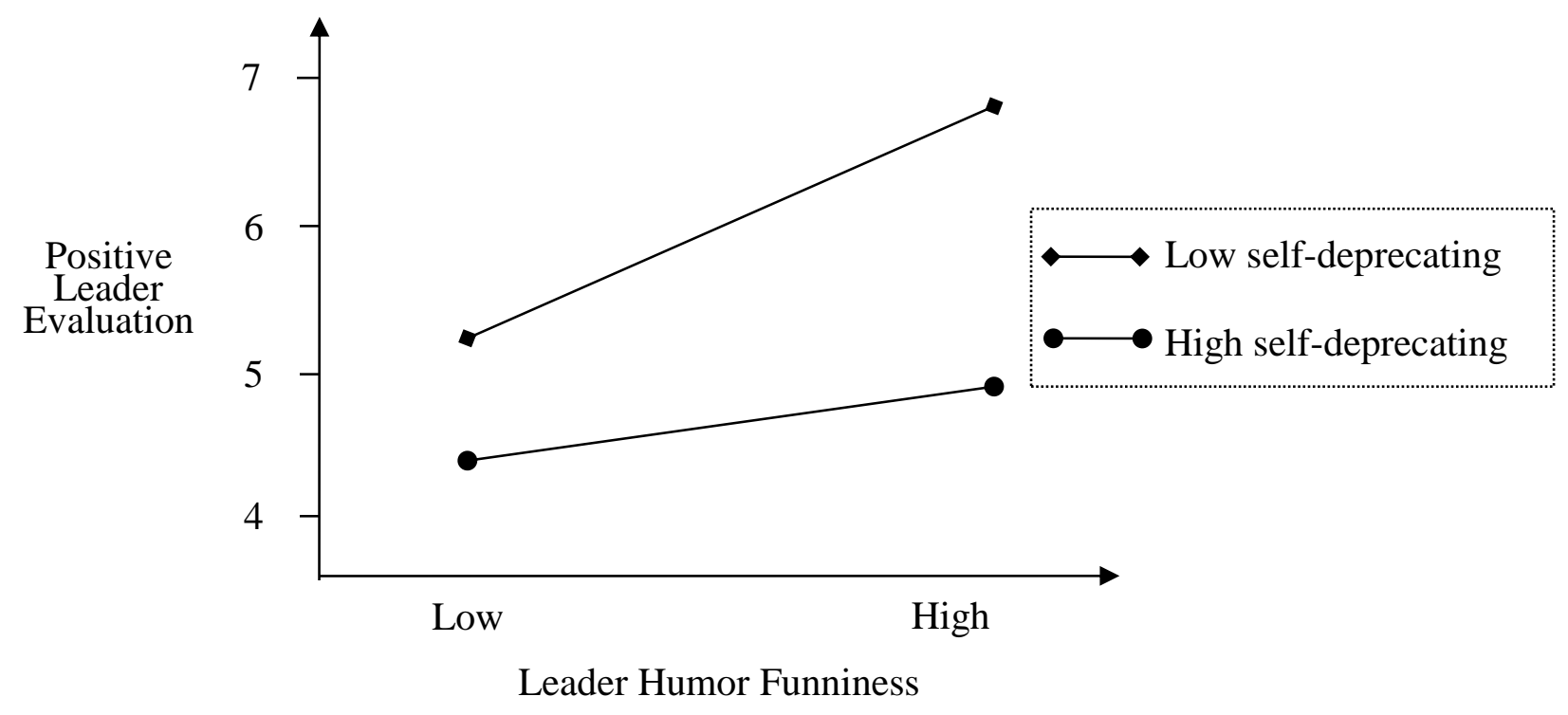

